\title{
A pesquisa como espelho dos nossos desejos
}

\section{The research of as a mirror of our desires}

\author{
Maristela Müller ${ }^{1}$
}




\section{Resumo}

O que a pesquisa pode dizer acerca do pesquisador? Como nossos gostos e desejos se revelam no objeto de investigação? Essas formam algumas perguntas que permearam a escrita do presente artigo, que busca questionar o que a pesquisa pode falar sobre quem a realiza. Nesse sentido, a pesquisa se apresenta como um espelho dos nossos desejos, pois reflete os gostos, amores e aspirações do pesquisador. Revela a capacidade de articular as evidências empíricas com os afetos explicativos. Mostra suas buscas e seu posicionamento, a partir do objeto e da teoria referenciada. $\mathrm{O}$ que mais está sendo refletido?

Palavras-chave: Pesquisa Acadêmica. Desejo. Pesquisador. Espelho. Refletir.

\section{Abstract}

What the research can say about the researcher? How our tastes and desires are revealed in the research object? These are some of the questions that permeate the writing of this article, which seeks to question what the research can reveal about their researcher. In this sense, the research is presented as a mirror of our desires, because it reflects the tastes, loves and aspirations of the researcher. Reveals the ability to articulate the empirical evidence with the explanatory affections. Showing your searches and positioning, from the object and the referenced theory. What else is being reflected?

Keywords: Academic research. Desire. Researcher. Mirror. Reflect.

ISSN: 2175-2346

\footnotetext{
1 Graduada no Curso de Licenciatura em Educação Artística (2010), pela UDESC - Universidade do Estado de Santa Catarina, onde participou como bolsista de extensão e iniciação científica em diferentes Projetos. Pós-Graduada em Pedagogia Gestora e Orientação Escolar (2011), pela FETREMIS - Faculdade de Educação e Tecnologia da Região Missioneira/RS. Brasil m-muller@hotmail.com
} 
Como falar de pesquisa se tudo parece ter sido dito? Essa foi uma das perguntas que norteou as aulas do Seminário de Pesquisa I, ofertada para o Mestrado e Doutorado no PPGAV/UDESC. Na tentativa de respondê-la, passou-se a pensar a pesquisa através de suas normas técnicas e metodológicas, mas também, em seus horizontes éticos e estéticos, em uma relação com acontecimentos cotidianos. Por exemplo: $A$ pesquisa como a preparação de um jantar; A pesquisa como a organização de uma casa/apartamento; A pesquisa como uma viagem; A pesquisa como travessia; A pesquisa como uma experiência amorosa; A pesquisa como o espelho dos nossos desejos.

Aproximar as características de uma experiência amorosa com o ato da pesquisa tornou-se uma tarefa instigante. Ambas são relações de encontros e desencontros. Desmesura e humildade. Errância. Fuga da mesmice. Energia. Doação. Desatino. Felicidades e tristezas. Insatisfação e plenitude. Impaciência e mansidão. Cansaço. Traição, medo, arrependimento e remissão. Ação e gozo, conforme as paixões se transformam em linguagem. Cada um e cada uma entende a complexidade dessas características de acordo com as relações amorosas que viveu ou vive. E quem, da mesma maneira, já passou pelo processo da pesquisa, também compreende esse misto de predicados que a afeta.

A relação amorosa é envolvente, assim como a pesquisa é envolvente, ao menos ao pesquisador que se lança no abismo em busca de respostas para aquilo que o atrai. Nesse sentido, a pesquisa se apresenta como um espelho dos nossos desejos. Ela reflete os gostos, amores e aspirações do pesquisador. Reflete a capacidade de articular as evidências empíricas com os afetos explicativos. Reflete sua busca e seu posicionamento, a partir do objeto e da teoria referenciada. Concomitantemente, encontra-se refletida nesse espelho uma interrogação. Toda pesquisa parte de uma pergunta. Uma dissertação ou uma "tese é mais do que uma boa idéia, é na essência uma boa pergunta." (FREITAS, 2002, p. 220), que se constitui a partir de um objeto de pesquisa elaborado e cuidadosamente delimitado.

A tese da Professora Dra. Sandra Makowiecky, por exemplo, defendida no Programa de Pós-Graduação Interdisciplinar em Ciências Humanas da UFSC, no ano de 2003, possui como objeto de pesquisa a representação da cidade de Florianópolis na visão dos artistas plásticos. Para isso, analisa as pinturas dos artistas selecionados, desde os viajantes do século XVIII e XIX até o final da década de 1990. Makowiecky desenvolve uma relação amorosa com sua pesquisa, pois investiga o lugar que nasceu e vive até hoje, que é Florianópolis/SC, vinculada a história e a representação dos artistas plásticos.

De modo semelhante, existe uma relação amorosa sendo vivenciada na pesquisa que realizo para o Mestrado, na qual se investiga tanto o estado do Rio Grande do Sul, quanto a região Missioneira ${ }^{1}$, onde nasci. A pesquisa busca refletir acerca da formação de professores pesquisadores nas Licenciaturas em Artes Visuais no RS. A investigação será realizada a partir do mapeamento das Instituições, públicas e privadas, que ofertam o curso presencial de Licenciatura em Artes Visuais, bem como,

\footnotetext{
1 Na região Missioneira há um problema social concreto, pois as duas IES que ofertavam Licenciatura em Artes Visuais tiveram seus cursos fechados, ou seja, não há mais formação de professores em Artes Visuais. No entanto, após manifestações populares a Universidade Federal da Fronteira Sul (UFFS), campus Cerro Largo/RS, dentro de sua política de extensão Universitária, solicitou a criação de um Instituto Federal de Arte e Cultura, na cidade de São Luiz Gonzaga/ RS. O Projeto está em tramite no Ministério.
} 
a análise Curricular dos cursos, com o foco nas disciplinas que colocam a pesquisa em evidência. Interligada a isso, haverá a revisão bibliográfica para costurar ponto a ponto, o tecido da investigação. O projeto de pesquisa visa contribuir com as ações desenvolvidas pelo Observatório da Formação de Professores de Artes Visuais, construído no início de 2011, sob a Coordenação da Profa. Dra. Maria Cristina da Rosa Fonseca da Silva, em âmbito nacional e no contexto da América Latina.

Retornando para a tese da Professora Sandra Makowiecky, ela se apresenta como uma reflexão teórica em 17 capítulos. Uma pesquisa que utiliza referencial teórico, imagens, percepções e sentimentos na história, que é algo recente em termos de objeto de trabalho para uma abordagem historiográfica, por isso esclarece que não se trata de uma iconografia histórica, mas de uma arqueologia poética. A proposta de trabalho é fenomenológica, nesse sentido, se compreende a realidade socialmente, onde existem diferentes interpretações entre o mundo objetivo e a subjetividade do sujeito.

As evidências empíricas da tese são trazidas através da cidade de Florianópolis como cidade real, na sua dimensão física, por meio de documentos, referencial teórico, pinturas e fatos históricos. Já, os afetos explicativos aparecem na sistematização desse trabalho, onde a autora proporciona plausibilidade ao recorte representacional (seleção de obras e artistas entre o século XVIII até o final da década de 1990), realizado acerca da cidade de Florianópolis. Os afetos explicativos também emergem tanto pelos olhos de quem vê a cidade e a representa nas pinturas selecionadas, quanto por quem busca refletir acerca dessas pinturas, ou seja, pelos olhos da própria autora.

Até o presente momento realizou-se uma aproximação entre as características da pesquisa com uma experiência amorosa. Mas, há um momento onde o ato da pesquisa não se coaduna com a experiência amorosa. A relação amorosa envolve, no mínimo, duas pessoas. Isso significa estar juntos em uma relação de reciprocidade. Já a pesquisa, muitas vezes, se converte em solidão. Escrever é estar só. Repetidas vezes, Marguerite Duras fala da solidão do autor e da solidão da escrita, uma solidão sem a qual nada se produz. "Nunca ninguém escreveu a duas vozes. Foi possível cantar a duas vozes, ou fazer música também, e jogar tênis, mas, escrever, não. Nunca." (DURAS, 1994, p. 22-23). Pode-se contra-argumentar ao dizer que o amor também é solitário quando sentido em segredo, ou quando endereçado a alguém que não corresponde. Mas, cabe lembrar que não se pretende aproximar as características do amor com a pesquisa e sim, da relação amorosa, onde necessariamente há duas ou mais pessoas envolvidas se relacionando.

Nesse momento escrevo, leio, penso e alimento a dissertação. Estou só no quarto organizando os referenciais teóricos, escrevendo textos, ao mesmo tempo, finalizando os componentes curriculares, indo a eventos e apresentando trabalhos. O que se pretende dizer é que, cada vez mais a dissertação exigirá escrita e momentos extensos de solidão, a fim de realizar a trama entre documentação (evidência empírica) e as plausibilidades (afetos explicativos) na pesquisa. Estão sendo utilizados instrumentos de coleta de dados como: mapeamento das IES públicas e privadas que ofertam o curso de Licenciatura em Artes Visuais no RS e a busca pelo currículo das IES, para depois realizar a análise minuciosa desses dados coletados, dentro da abordagem sócio-histórica. O período é de construção. Colocar no papel o que amoro- 
samente se pesquisou, em meio a insatisfação e plenitude. O momento é de solidão.

A pesquisa como espelho dos nossos desejos reflete nossos gostos e concepções. Trazer essa colocação para o objeto da minha pesquisa significa dizer que, uma formação de professores em Artes Visuais, com qualidade, pode ocorrer a partir da pesquisa. Com o incentivo a pesquisa, ao longo da graduação, o estudante amplia conhecimentos, enriquece o vocabulário, o repertório, a escrita e a argumentação, desenvolve segurança no falar e apresentar, expande a percepção, o senso crítico, o raciocínio, a capacidade de construir relações, perceber a realidade, elaborar problemas, objetivos, traçar metas, buscar cumprir aquilo que se propôs, não se acomodar, ler constantemente na busca de ampliar seu fôlego para a leitura, construir e reconstruir saberes e assim, aos poucos, conquistar autonomia. Aos poucos vai se torando um estudante que pesquisa para depois se tornar, na ação em sala de aula, um professor pesquisador. Evidente que isso não ocorre espontaneamente, mas com muita dedicação e querer, com resiliência e serendipidade.

Por hora vivo a Dissertação. Vivo a escrita. Essa aventura de escrever, na qual não se sabe ao certo aonde chegar. Também busco parceiros(as) que encontro no Observatório da Formação de Professores de Artes Visuais, onde algumas características das pesquisa se aproximam. Por enquanto a relação amorosa com a pesquisa está em meio a constantes tentativas, errâncias e acertos. Entre a insatisfação e a plenitude. Energia e cansaço. Ação e gozo. Para as para a próxima etapa da pesquisa guardo uma certa apreensão, pois serão dias solitários de escrita. Desejo que as paixões se transformam em linguagem e que a pesquisa se converta no espelho de nossos desejos, a fim de que haja contentamento nas ações e aprendizagem a cada experiência.

\section{Referências}

DURAS, Marguerite. Escrever. Trad. de Rubens Figueiredo. São Paulo: Rocco, 1994

FREITAS, Maria Ester de. Viver a Tese é preciso! In: BIANCHETTI, Lucídio, MACHADO, Ana Maria (orgs.). A bússola do escrever: desafios e estratégias na orientação de teses e dissertações. 3ạ Ed. São Paulo: Cortez, 2002.

MAKOWIECKY, Sandra. A representação da cidade de Florianópolis na visão dos artistas plásticos. Florianópolis: DIOESC, 2012. 